\title{
Solid Dosage Form
}

National Cancer Institute

\section{Source}

National Cancer Institute. Solid Dosage Form. NCI Thesaurus. Code C45235.

A substance having definite shape and volume manufactured for the administration of active and/or inert ingredient(s). Solids include tablets, capsules, powders, granules and certain suppositories. 